Correspondence

\section{An unusual cause of post operative respiratory distress following anterior cervical discectomy and fusion}

\section{Himanshu Goyal, Surya K Dube, Ajay Kumar ${ }^{1}$, Keshav Goyal}

A 25-year-old $58 \mathrm{~kg}$ ASA 1 male was scheduled for an anterior cervical discectomy and fusion (ACDF) for traumatic prolapsed inter vertebral disc (PIVD) at third and fourth cervical vertebra (C 3-4) level. His routine blood investigation and airway examination was within normal limits. In the operating room (OR) patient's trachea was intubated with an $8.5 \mathrm{~mm}$ polyvinyl chloride (PVC) cuffed endotracheal tube (ETT) under general anesthesia using a videolaryngoscope and stylet. His Cormac Lehane (CL) grade was 3. The patient had a stable intraoperative course and after the procedure patient's trachea was extubated in OR and he was shifted to intensive care unit (ICU) for observation.

In the ICU after 6 hours the patient complained of respiratory distress. His blood oxygen saturation $\left(\mathrm{SPO}_{2}\right)$ dropped from $100-85 \%$ with no hypotension or auscultatory chest abnormality. There was no visible neck swelling, the suture line was intact without any leak from the incision site and surgical drain content was minimal. The arterial blood gas (ABG) of the patient revealed a $\mathrm{pH}$ of 7.20, partial pressure of oxygen in arterial blood $\left(\mathrm{PaO}_{2}\right)$ of $80 \mathrm{~mm} \mathrm{Hg}$ and a partial pressure of carbon dioxide $\left(\mathrm{PaCO}_{2}\right)$ of $56 \mathrm{~mm} \mathrm{Hg}$. Assisted manual bag and mask ventilation

Departments of Neuroanaesthesiology, ${ }^{1}$ Anesthesiology, Jai Prakash Narayan Apex Trauma Center, All India Institute of Medical Sciences, New Delhi, India

Address for correspondence:

Dr. Keshav Goyal, Department of Neuroanaesthesiology, $7^{\text {th }}$ Floor, CN Center, All India Institute of Medical Sciences, New Delhi, India.

E-mail: keshavgoyal@yahoo.co.in 


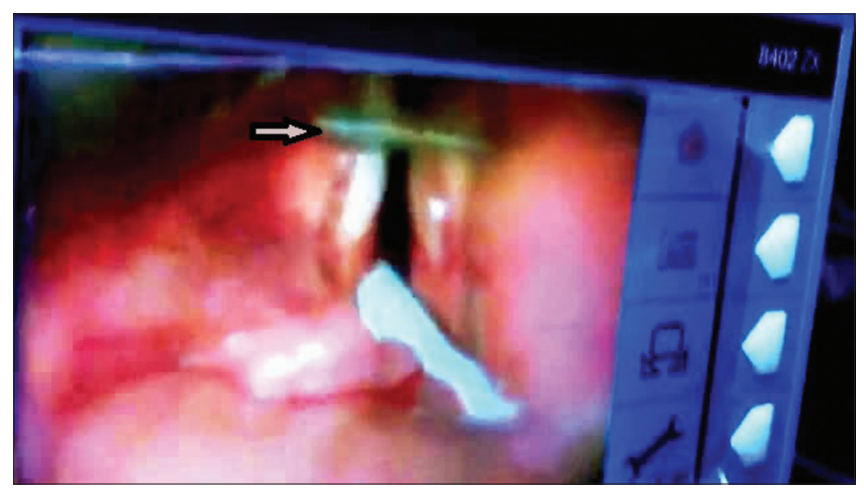

Figure 1: Videolaryngoscopic view of laryngeal inlet showing surgical drain (arrow mark) in front of vocal cord. The lower part of the larynx is showing the bougie inside the laryngeal inlet

was started and we attempted endotracheal intubation with a direct laryngoscope under propofol sedation and manual in line stabilization (MILS). But the view was compromised by poor visualization of the upper airway landmarks and edema of the pharyngeal wall. We tried to insert a tracheal tube over a bougie but could not negotiate the ETT into the patient's trachea due to resistance near vocal cords. Following two unsuccessful attempts of intubation we reattempted tracheal intubation with a videolaryngoscope and MILS. The videolaryngoscopic view revealed a horizontal cord-like structure in front of the vocal cords [Figure 1]. Under video laryngoscope guidance, a $7 \mathrm{~mm}$ ETT was negotiated into the trachea with the help of a bougie. Patient's lungs were mechanically ventilated thereafter and an ABG after 2 hours revealed a $\mathrm{pH}$ of $7.36, \mathrm{PaO}_{2}$ of $142 \mathrm{~mm} \mathrm{Hg}, \mathrm{PaCO}_{2}$ of $33 \mathrm{~mm} \mathrm{Hg}$. A Cervical X-ray done subsequently revealed a radio opaque cord like structure (surgical drain) in the neck [Figure 2] which was immediately removed by surgeon, which probably was due to improper placement by surgeons. Patient's trachea was extubated after 24 hours. He had an uneventful ICU stay there after.

Airway obstruction within hours of tracheal extubation may be related to residual neuromuscular blockade or hypoventilation from narcotic medication. ${ }^{[1,2]}$ In our case this probability was ruled out as the patient had a stable course for initial 6 hours postoperatively. Upper airway compromise in the immediate postoperative period (within 12 hours) following ACDF surgery mostly occurs due to an expanding wound hematoma. ${ }^{[1]}$ But, in our case the suture line was intact, with no

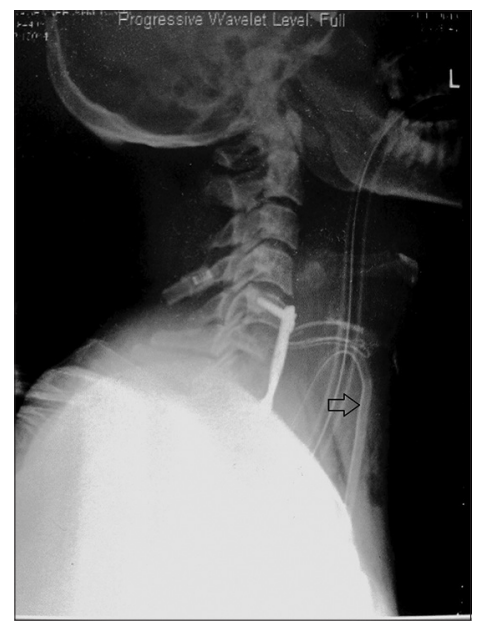

Figure 2: Lateral cervical $\mathrm{X}$ ray showing surgical dra

visible neck swelling or high output in the surgical drain. Delayed hematoma and alternative causes of airway obstruction like pharyngeal/prevertebral edema, spinal construct failure, cerebrospinal fluid (CSF) collection or retropharyngeal abscess can be the probable causes of respiratory obstruction following ACDF beyond the first 12 hours ${ }^{[3]}$ But in our case the cause of airway obstruction was unique, that is a post surgical drain tube. So we suggest that in case of respiratory distress after ACDF surgery one should consider the possibility of a malpositioned surgical drain and hence prepare accordingly to deal with it.

\section{REFERENCES}

1. Palumbo MA, Aidlen JP, Daniels AH, Thakur NA, Caiati J. Airway compromise due to wound hematoma following anterior cervical spine surgery. Open Orthop J 2012;6:108-13.

2. Kervin MW. Residual neuromuscular blockade in the immediate postoperative period. J Perianesth Nurs 2002;17:152-8.

3. Palumbo MA, Aidlen JP, Daniels AH, Bianco A, Caiati JM. Airway compromise due to laryngopharyngeal edema after anterior cervical spine surgery. J Clin Anesth 2013;25:66-72.

\begin{tabular}{|l|l|}
\hline \multicolumn{2}{|c|}{ Access this article online } \\
\hline Quick Response Code: & Website: \\
\hline & www.jnaccjournal.org \\
\cline { 2 - 2 } & \\
\hline & \\
\hline
\end{tabular}

